\title{
ARTÍ́CULOS
}

\section{AMBIVALENCIAS Y TRANSFORMACIONES DE LAS FIESTAS NEOBAKALAS}

\author{
AMBIVALENCES AND TRANSFORMATIONS OF NEOBAKALA FESTIVITIES
}

\section{Eduardo Leste Moyano ${ }^{1}$}

\author{
Investigador independiente
}

Recibido: 24 de septiembre de 2018; Aprobado: 8 de julio de 2019

Cómo citar este art culo / Citation: Leste Moyano, Eduardo. 2020. «Ambivalencias y transformaciones de las fiestas neobakalas». Disparidades. Revista de Antropología 75(2): e020. doi: <https://doi.org/10.3989/dra.2020.020>.

RESUMEN: Este artículo explora, a partir de fuentes etnográficas, la forma en que los miembros de la escena musical neobakala lidian, mediante prácticas rituales y carnavalescas, con los estados afectivos derivados de la vida urbana en el capitalismo tardío. Con este fin, este trabajo toma como referencia la propuesta teórica y metodológica sobre la afectividad de Alexandre Surrallés (2005 y 2009). En este sentido, este texto se adentra en el cuerpo y la persona capitalista para, a partir de ahí, identificar contex-tualmente sus estados de ánimo, sus relatos identitarios y los grupos sobre los cuales este relato se despliega y repliega. En este plano afectivo, este trabajo, donde la nostalgia es un aspecto central, también tiene en cuenta otros aportes hechos, de nuevo, desde la antropología, como son los de Appadurai (2001) o Hirai (2009). Por último, el artículo se adentra en las relaciones entre la nostalgia y la memoria y muestra cómo, en este caso, la memoria parece erosionarse por la acción de la nostalgia.

PALABRAS CLAVE: Afectividad; Cuerpo; Rituales; Carnavales; Capitalismo.

ABSTRACT: This article ethnographically explores how the neobakala music scene creates ritual and carnivalesque practices to deal with the affective states produced by late capitalism in urban societies. To this end, this study takes as its point of reference the theoretical and methodological proposal of affectivity suggested by Alexandre Surrallés (2005). The article therefore explores the capitalist body and personhood, and identifies its affective states and identity discourses to see how these are projected and re-flected. The paper also considers the contributions to the understanding of nostalgia made by Arjun Appadurai (2001) and Sinji Hirai (2009) and finally explores its relations with memory, revealing that, in this case, nostalgia seems to erode memory.

KEYWORDS: Affectivity; Body; Rituals; Carnivals; Capitalism.

Copyright: (C) 2020 CSIC. Este es un artículo de acceso abierto distribuido bajo los términos de la licencia de uso y distribución Creative Com-mons Reconocimiento 4.0 Internacional (CC BY 4.0).

1 Correo electrónico: eduleste@gmail.com. ORCID iD: <https://orcid.org/0000-0002-0957-9253>. 


\section{INTRODUCCIÓN}

Los bakalas conformaron una cultura juvenil (Feixa 1998) que se manifestó por distintas ciudades españolas, como Valencia o Madrid, en el primer lustro de los años noventa. En Madrid, estos bakalas ${ }^{2}$ crearon una estética particular hecha a base de marcas de ropa (zapatillas New Balance, pantalones Levi's, camisetas Powell Peralta y los plumíferos Pedro Gómez) y una práctica que denominaron «la fiesta». Para estos bakalas, irse "de fiesta» suponía salir a ciertas discotecas, como Nuclear Zone o Zolex ${ }^{3}$, lugares a los que asistían para bailar con sus amigos, muchas veces durante días. En aquellos años, salir «de fiesta» implicaba estar "de buen rollo», algo que entendían así:

Nuclear Zone yo lo recuerdo [...] de muy buen roIlo... por ejemplo... tú estabas bailando y gente que no conocías de nada te podía ofrecer la copa, te podían dar un trozo de pastilla, ofrecer un canuto... lo que es buen rollo... la gente se presentaba... había empatía... (César).

Lo que nos enamoró a todos es que un tío podía decirle a otro tío... 'Me cago en la puta, toma un cacho de pastilla' y se daban un abrazo y nadie iba a pensar nada malo ni ibas a ser más blando por eso y era fantástico porque todo el mundo estaba por la labor de que todo estuviera bien. Y te empujaban lo más mínimo al pasar y no te decía 'perdona'... No, te decían 'perdona' [enfatiza]. Y te querían dar un cacho de pastilla porque te habían empujado un poco. Es decir que nada rompa esta magia (Marta).

La gente lo gozaba [...] se ponía a bailar a toda... y veías a la gente, y la gente te veía... y era el verte... como si te estuvieras mirando en un espejo (Alberto).

El «buen rollo» que había en «la fiesta», por tanto, estaba relacionado con bailar, ofrecer, invitar, presentarse, tener empatía, abrazarse, dejar de lado la representación estricta de la masculinidad o perdonar.

2 En otras partes (Leste 2018) he diferenciado entre bakalas y vakalas, situando la cultura bakala entre 1990 y 1992, y la vakala entre 1993 y 1996. Para ello enfatizaba ciertos matices estéticos y musicales de los vakalas. En este texto, en el que principalmente trato el presente, es decir, la escena neobakala, no me adentro en estos detalles y hago referencia a su pasado de la forma más genérica posible, es decir, como bakalas.

3 Los nombres de las discotecas y de los informantes han sido cambiados.
Todo esto lo hicieron al ritmo de distintas músicas electrónicas de carácter innovador, ecléctico y transgresor, que llamaron bakalao (hardcore 4 y trance ${ }^{5}$ ), y con una serie de tecnologías y medios: mesas de mezclas, vinilos, casetes, éxtasis, hachís, alcohol y LSD. El resultado fue una experiencia de gran potencial comunicativo con la que subvirtieron el control parental, que recuerda mucho a la communitas descrita por Turner, ese «sentimiento de entendimiento mutuo en un nivel existencial» (Turner 1982: 48), y a la teoría del don (Mauss 2002): dar, recibir y reciprocar. En cualquier caso, musicalmente hablando, conviene señalar que, en estos años, los bakalas no tenían un conocimiento demasiado preciso de la música que bailaban. Como me relató César, una de las personas con las que trabajé durante la etnografía: «entonces no sabíamos mucho de música, [...] éramos gente que íbamos a escuchar música y cogernos el pedo». La "fiesta» y el bakalao, por tanto, tenían más de práctica corporal y sensible, que de discurso verbal. El conocimiento musical quedaba entonces en manos de los $D J$ que, por otro lado, no gozaban de un prestigio especial. Era un empleado de sala como cualquier otro.

Esta cultura juvenil, en la que participaron jóvenes de distintas clases sociales, que nació en un contexto de inserción capitalista ${ }^{6}$, de precariedad laboral, de expansión mediática y de subalternidad juvenil (Leste 2018), desapareció en el segundo lustro de los noventa debido, en parte, a ciertos cambios que se produjeron en el mismo contexto que la había alumbrado. En este sentido, los efectos de la crisis económica de 1993, la cobertura mediática -que transformó el bakalao en un pánico moral- y la represión política ${ }^{7}$ comprometieron la continuidad de esta cultura. Además, el propio envejecimiento de sus participantes hizo que muchos de ellos dejaran de salir «de fiesta». La mayoría de los bakalas dejaron atrás su filiación juvenil y fueron transitando a la adultez. Compraron casas, tu-

4 Música electrónica de principios de los años noventa caracterizada por su especial intensidad.

5 Estilo musical que se prodigó por Europa a partir de 1993 en sus múltiples vertientes: trance, hardtrance, etc. Suele superar al hardcore en intensidad.

6 Madrid entraba en estos años en el capitalismo financiarizado.

7 A partir de 1993 el gobierno socialista decidió acabar con el bakalao, especialmente en su versión valenciana aplicando la Ley Corcuera. En Madrid, el PP quiso aplacar el fenómeno sancionando administrativamente a las discotecas bakalas (Leste 2018). 
vieron hijos e incluso iniciaron sus pequeños negocios en aquellos años en los que el gobierno popular dio rienda suelta a la burbuja inmobiliaria (Leste 2018). Fue así como se extinguió la cultura bakala, que hoy es objeto de nostalgia de los neobakalas.

\section{BREVES APUNTES METODOLÓGICOS}

Antes de comenzar a hablar de los neobakalas, no obstante, conviene señalar ciertos aspectos teóricometodológicos que sirven como punto de referencia a la estructuración de este artículo, que se centra en las fiestas de estos sujetos. Para abordarlas, este texto parte del trabajo de Turner (1982 y 1988) y su forma de analizar la ritualidad, es decir, entendiendo que los sucesos que en ella se producen están vinculados a las contingencias de la vida ordinaria y su estructura social. Esto hará que, en cierto modo, este artículo se pueda dividir en tres partes: una primera, en la que atenderé a la estructura y el contexto social y cultural de la vida cotidiana de estos sujetos; una segunda, en la que desarrollaré el funcionamiento y los sucesos de su vida ritual; y una tercera, en la que analizaré las dos primeras partes de forma interconectada, desgranando sus aspectos rituales y carnavalescos y su potencialidad transformadora. La primera parte quedará condensada en los epígrafes «Los neobakalas» y "Las fiestas neobakalas», que trataré a continuación. La segunda, quedará desplegada a caballo entre el apartado anterior y el epígrafe «Relato de una fiesta neobakala». Y, la tercera, en el resto de apartados.

Este artículo, de todas formas, no pretende ser un mero análisis turneriano de una práctica ritual occidental relacionada con la música electrónica, algo que ya se ha hecho, con más o menos acierto, por otros autores (St. John 2008), sino que busca vincularla con la afectividad de los neobakalas. Con este fin, este artículo toma como referencia el trabajo de Alexandre Surrallés, que resulta especialmente valioso por dos motivos. Primero, porque la aproximación de Surrallés (2003) a los rituales permite interpretar sus significados no tanto por los textos que en ellos se puedan enunciar, como por las interacciones perceptuales, sensoriales y afectivas que en ellos se producen $^{8}$, y esto, en el caso de las fiestas neobaka-

8 Integrar en mi análisis las cosas que se dicen con palabras con aquellas que se dicen con el cuerpo (e incluso la mis- las, donde sus participantes y su música son más bien parcos en palabras, será de gran utilidad. Y, segundo, porque el trabajo de Surrallés (2005 y 2009) permite hacer de la afectividad un campo propio de reflexión antropológica y conectarlo con ámbitos característicos de esta disciplina, como son la corporalidad y las relaciones con la otredad. En el nivel metodológico, entender la afectividad desde este punto de vista supondrá identificar, por un lado, cómo el cuerpo, la persona y los sentidos son entendidos y organizados en la cultura local ${ }^{9} y$, por otro, definir la percepción de la relación con la otredad en una doble dirección, la que se establece por medio del repliegue del otro en mí -interoceptividad-y la que se establece por medio del despliegue «mío en el otro»-exteroceptividad- (Surrallés 2009: 38). En el caso de los neobakalas esta forma de acercarse a la afectividad supondrá contextualizar sus cuerpos dentro de sus propios referentes culturales y, además, identificar la forma en que estos sujetos se despliegan y repliegan sobre los otros, que en el caso de los neobakalas son otras escenas musicales (aquellas sobre las que se proyecta el relato nostálgico y por medio de las cuales construyen su identidad). En este sentido, el concepto de escena (Straw 1991), con su énfasis en la interacción, será especialmente pertinente, ya que servirá para precisar quiénes son los otros para los neobakalas y definir el estilo u objetivos de la relación. Estos aspectos serán interpretados como parte de la estructura social y cultural y quedarán recogidos en el epígrafe de «Los neobakalas».

En otro orden de cosas, este artículo está elaborado a partir de fuentes etnográficas extraídas de redes so-

ma idea de transformación de los afectos que veremos en el caso de las fiestas neobakalas) debe mucho a la metodología seguida por Surrallés en su interpretación de las ceremonias de bienvenida practicadas por los candoshi. Este artículo, por tanto, tiene algo de metodología indígena (Micarelli 2018) solo que en este caso empleo las etnografías indígenas (amerindias) como recurso reflexivo, como punto a partir del cual poder pensar aquello que, de otra forma, daría por sentado. No comparto con Micarelli la idea de emplear metodologías diferenciadas, unas para mundos «encantados» (indígenas) y otras para mundos "desencantados» (occidentales), porque esto implica pasar por alto que los magos más poderosos se encuentran en centros de poder, como el sector bancario (Appadurai 2016). De hecho, faltan etnografías en estos espacios (Anta 2007).

9 Establecer el punto a partir del cual se organiza tanto el sentido común como las posibilidades de sueño de los sentidos (Gutiérrez Estévez 2006). 
ciales y, sobre todo, a partir de múltiples entrevistas en profundidad que se suman a mis observaciones, interacciones y experiencias en el trabajo de campo durante las fiestas neobakalas. En este sentido, conviene aclarar que todo el entramado teórico-metodológico está orientado a explicar esta etnografía, de tal forma que lo primero siempre se acoplará a lo segundo (y no al revés). Esto permitirá recoger ciertas ambivalencias que se dan en estos eventos, donde lo ritual, lo festivo, lo carnavalesco y lo ceremonial coexisten, a pesar de que autores como el propio Turner (1982) o Bajtin (1989) intentaran separarlos. Por otro lado, estos datos etnográficos tienen un tratamiento particular en el epígrafe «Relato de una fiesta neobakala». En él trataré de entreverar datos recurrentes y especialmente significativos de las fiestas, de tal forma que la descripción funcione como síntesis de las cosas que suceden en estos eventos. Por otro lado, con este relato, en el que los participantes aparecerán como personajes de una novela, espero poder acercar al lector a las experiencias, sensaciones, percepciones y subjetividades de unos protagonistas entre los cuales está el autor de estas páginas. La etnografía, por tanto, se movió entre la observación y la objetivación participante (Bourdieu 2003). En este sentido, durante las noches de trabajo de campo en las fiestas neobakalas hubo fases en las que primó la observación y otras en las que lo hizo la participación. En cualquier caso, tanto la observación como la participación fueron acompañadas de un doble proceso de reflexión teórica y personal, que giró, por un lado, en torno a las observaciones y experiencias que tuve durante el trabajo de campo y, por otro, alrededor de mi propia nostalgia, que durante un tiempo se alineó con la de los neobakalas ${ }^{10}$.

Desvincularme de mi propia nostalgia tuvo algo de decepcionante (e incluso doloroso) pero me ayudó a tomar perspectiva con mi propio objeto de estudio y a alejarme de interpretaciones descontextualizadas de la ritualidad (St. John 2014). Pero, además, me ayudó a entender las sutiles y cruciales diferencias entre nostalgia y memoria, en tanto que la primera tiene más de presente que se incrusta y embellece el pasado, y la memoria más de pasado que se incrusta en el presente, con su correspondiente potencial crítico (Tomé 2016 y 2017). Es por esto por lo que, a lo largo del texto, he entrecomillado verbos que usan los neobakalas, como «recordar» y «recuperar», porque son formas de hablar

10 En mi adolescencia tuve vinculación personal con la cultura bakala. que, en principio, hacen pensar en un ejercicio de memoria, cuando en realidad, en el caso que aquí trato, es más bien un ejercicio de nostalgia. En este sentido, este artículo también puede ser entendido como crítica cultural (Marcus y Fischer 1986). Dicho esto, pasemos a ver el contexto social y cultural de los neobakalas y cómo estos construyen su identidad.

\section{LOS NEOBAKALAS}

Los neobakalas conforman una escena musical integrada básicamente por adultos que fueron bakalas y que, en la actualidad, reformulan nostálgicamente aquella cultura. Se trata de sujetos cuyas vidas transcurren muchas veces en barrios obreros o pueblos aledaños de una ciudad global, Madrid (Observatorio metropolitano 2007). Se trata, por tanto, de personas que viven alejadas de los centros de poder de estas ciudades y que suelen verse negativamente afectadas por las consecuencias del capitalismo globalizado: procesos de desterritorialización y destemporalización, creciente desigualdad, precariedad laboral, exclusión social y, en definitiva, inseguridad material y simbólica. Consecuencias, a su vez, acentuadas por un nuevo entorno hiperdigital (Feixa, Fernandez-Planells y Figueras-Maz 2016) que crea nuevos espacios de interacción social y acelera una circulación de imágenes, músicas o textos que enfatiza los ya mencionados procesos de desterritorialización y destemporalización (Leste 2018). En este contexto de discontinuidades y rupturas sociales y temporales, los neobakalas, personas generalmente de clase trabajadora, afrontan su adultez. $Y$ lo hacen con recursos muy limitados en una sociedad capitalista marcada por la lucha por el prestigio a través del consumo material y simbólico, algo que deriva en un estado afectivo en el que abundan los sentimientos de alienación, insatisfacción y frustración, que en ocasiones se traducen en agresividad, especialmente en el caso de los hombres ${ }^{11}$. Los neobakalas son personas que viven en un mundo que perciben como incierto, caótico y hostil, donde, como algunos de ellos dicen, "la gente no sabe decir por favor o gracias». Y lo hacen en una adultez prácticamente rota ${ }^{12}$ y llena de cargas.

11 Probablemente porque esos hombres no pueden cumplir con ciertos roles de la masculinidad contemporánea (García 2008).

12 Debido a la crisis de 2008 y a las medidas neoliberales aplicadas para salir de ella las condiciones materiales de 
Inseguridad, frustración, insatisfacción o agresividad son el resultado afectivo de un cuerpo neobakala que, producido en el capitalismo, está hecho para consumir, poseer y dominar al otro, aunque no siempre pueda hacerlo. Un cuerpo que, por otro lado, sostiene una idea de persona que se basa en la dualidad o separación, perfectamente delimitada, de cuerpo y alma (mente), de interior y exterior, de tú y yo, de naturaleza y cultura, de hombre y mujer, de pensamiento y sentimiento ${ }^{13}$, pero que, a la vez, es interpretada como sujeto aislado e indivisible (como un individuo). Una idea de persona cuyo ideal aspira, por tanto, a la unicidad y a la unidad, a la que le cuesta vivir con la fragmentación ${ }^{14}$, con lo "poli», porque se sustenta en lo «mono ${ }^{15}$. Una idea de persona que, por consecuencia, busca ontologías, esencias, raíces, orígenes, en lugar de interrelaciones (Said 2001). Una idea de persona un tanto colonial o colonialista que, privilegiando la vista como centro sensorial (Levin 1993) ${ }^{16}$, mira y juzga, como sugería Bhabha (1994), y que, por ende, se basa en relaciones de dominación tanto hacia su interior como hacia su exterior. Una persona que, además, se satisface con "tener», del latín tenere, que puede ser traducido por dominar o retener. Una persona que busca muchas veces la con-tención, la con-tinuidad y, sobre todo, estar con-tenta: toda-junta (con) + dominadaretenida (tenta). Una persona que muchas veces está con-tenta cuando con-sume pero que, por el contrario, cuando no puede con-sumir se ve abocada a las tristezas, a los derrumbes, a las descomposiciones.

Encarnados en estos cuerpos, y como respuesta a este estado afectivo, los neobakalas producen nostalgia, un sentimiento muy propio del capitalismo

las clases sociales a las que pertenecen los neobakalas se deterioran y, con ellas, las posibilidades de hacer frente a las responsabilidades socialmente establecidas para la adultez.

13 Pares opuestos interpretados como complementarios, jerarquizados.

14 Vivimos la fragmentación con tanta angustia que a la enfermedad mental por excelencia la hemos denominado esquizofrenia. Por contra, en otras culturas, como las amerindias, la fragmentación de la persona es vivida con normalidad (Gutiérrez Estévez 2009).

15 Espacio donde gobierna el principio de no contradicción (Gutiérrez Estévez 2009), de carácter masculino, que esconde y revela el tabú occidental contra la homosexualidad (Butler 2007).

16 Esto no quiere decir que el resto de sentidos no jueguen papeles importantes en las sociedades occidentales (Connor 2004).
(Appadurai 2001; Hirai 2009; Tomé 2016; Leste 2020) que se ha acentuado en los últimos años, especialmente a partir de la crisis financiera de 2008 (Leste 2018). Es alrededor de la nostalgia, con su poder evasivo, que estas personas organizan su identidad.

$Y$ es que, para construir su identidad, los neobakalas recurren a fragmentos de su pasado, como la música bakalao, las tecnologías analógicas (los sintetizadores y el vinilo - pinchado a mano-) y algunas de las prácticas de los bakalas («la fiesta» - desexualizada- y el "buen rollo») y lo transforman en un discurso nostálgico, que ahora ya no busca subvertir un control parental sino dominar a otras escenas con las que se relacionan: el reggaeton ${ }^{17}$, la $E D M^{18}$ y lo que ellos denominan el minimal-techno ${ }^{19}$. Es en contraposición a estas otras escenas que los neobakalas organizan su identidad. De esta forma, los neobakalas rechazan el reggaeton por su exceso de «sexualización»; la EDM por estar protagonizada por $D J$ 's que llevan sesiones pregrabadas, que usan tecnologías digitales (el mp3) en lugar de analógicas (el vinilo) y que son seguidos por jóvenes que no tienen ni «historia» ni «cultura»; y el minimal-techno porque sus DJ no son «profesionales» y no se «esfuerzan» (Ricardo Villalobos, por ejemplo), y porque es una escena llena de personas "que van a exhibir cuerpo" y no les gusta la electrónica «de verdad». Para los neobakalas, en definitiva, la música, la tecnología y las prácticas de estas otras escenas son consideradas peores que las suyas. Son menos auténticas ${ }^{20}$. Frente a ellos, la escena neobakala elabora un discurso nostálgico que les facilita pensarse como un grupo «auténtico» con «esencia», con «historia», con «cultura»:

Los niñatos no pintan nada en este tipo de eventos, yo no dejaba pasar a menores de 28 porque esas generaciones [...] ni vivió el espíritu de Zolex y de la buena fiesta, del buen rollo. [Si no vinieran] ya seríamos los de siempre, los del buen rollo de antaño. [A los jóvenes] No les importa la música, solo

17 Género musical nacido en Centroamérica a mediados de los noventa que se expandió de forma transnacional a partir del cambio de siglo (Martínez Noriega 2014).

18 Acrónimo de Electronic Dance Music que se usa para referirse a la escena musical protagonizada por jóvenes que siguen a DJ como Steve Aoki.

19 Se caracteriza por ser una música lineal producida con medios digitales.

20 Los neobakalas hacen de la nostalgia un objeto con pátina (Appadurai 2001). Así aseguran la fuente de su autenticidad, colocándola en un tiempo al que los demás nunca podrán acceder. 
van pa ponerse ciegos de éxtasis, no tienen cultura musical de la época de los 90 (Ramón).

El hardcore, el trance, el vinilo, "la fiesta» y su desexualización, el «buen rollo» o el esfuerzo físico conforman, por tanto, su discurso identitario. Son parte de su ideología. Son los instrumentos que los neobakalas usan para desplegarse sobre "los otros», los jóvenes o los reggaetoneros, que muchas veces son vistos como "torpes» o "viciosos», porque solo van a las fiestas, como dice Ramón, para ponerse «ciegos de éxtasis» ${ }^{21}$. Estas relaciones con los otros se dan, principalmente, en Internet, que es donde discurre la vida ordinaria de los neobakalas en tanto que neobakalas.

\section{LAS FIESTAS NEOBAKALAS}

Estas personas, no obstante, no solo elaboran una ideología que, en forma de discurso primordialista, les permite proyectarse sobre estas otras escenas o grupos sociales con los que se relacionan, sino que, además, lo llevan a la práctica, lo obran. En su afán por "recuperar» y «conservar» el pasado, los neobakalas retoman la práctica de "la fiesta», que muchas veces se conoce como remember, porque su objetivo, según dicen, es «recordar»:

Nuestras reuniones puntuales se crearon para recordar y rememorar una época dorada de la música electrónica vivida en los años 90 . Un punto de inflexión en el camino de la vida de muchos de nosotros que nunca más volverá porque ya sucedió, pero con cada una de nuestras reuniones puntuales volvemos a vivirlo todos juntos (Julio, promotor de Zolex).

Sí, el pasado «nunca más volverá porque ya sucedió» pero, como dice Julio, a través de las fiestas se puede retornar a él, "volver a vivirlo». Con este fin, para poder revivir el pasado, "recordarlo» a través de sus fiestas, los neobakalas estipulan unas reglas tácitas que deben cumplirse en las mismas. Son las que deben garantizar que estos eventos son «como en el pasado». En primer lugar, la música de la fiesta ha de ser "pura», es decir, pertenecer exclusivamente a la citada en la introducción: hardcore o

21 Para "cogerse el pedo», diría César, el bakala de la introducción. trance ${ }^{22}$ de entre 1990 y 1996 . No puede sonar nada posterior en el tiempo o de otros estilos. En segundo lugar, se debe pinchar con vinilo. No se aceptan las controladoras o programas informáticos que automatizan las mezclas musicales ${ }^{23}$, como Ableton. En tercer lugar, la música ha de ir de menos a más. Cada tema tiene su momento. En cuarto lugar, la música ha de sonar nítida y contundente, «que retumbe en el pecho», como en el pasado. En quinto lugar, a las fiestas se va "de buen rollo", como antaño. Y, por último, los participantes han de saber comportarse, no pasarse en la embriaguez y no intentar ligar. La pista de baile ha de estar desexualizada. Estas son las seis reglas básicas que deben asegurar poder "revivir» la experiencia de la fiesta bakala, que tanto tenía que ver, recordemos, con la communitas. Estas reglas están destinadas, en definitiva, a subsanar la ruptura temporal entre el pasado (el bakalao) y el presente (el neobakalao). En este sentido, junto a estas reglas, establecen toda una serie de elementos de continuidad temporal con el bakalao, como es privilegiar en la contratación a los $D J$ que trabajaron en las discotecas del bakalao o hacer coincidir sus fiestas con los aniversarios de las discotecas bakalas, es decir, con su fecha de apertura. En este sentido, los aniversarios son fechas importantes para los neobakalas, llegando a marcar su calendario anual. Todos saben cuándo se celebra el aniversario de Zolex y lo esperan con ansiedad. Es su tiempo extraordinario.

Las fiestas neobakalas, por otro lado, se hacen siempre en discotecas, a poder ser, en las salas bakalas originales. Los neobakalas no establecen normas de etiqueta para la asistencia a sus eventos, aunque en muchas ocasiones discriminan por la edad, no dejando pasar a personas demasiado jóvenes. Esta discriminación siempre se hace en la puerta, donde se cobra una entrada que suele rondar los 20 euros. En cuanto a la distribución física del espacio dentro de la discoteca, este está segmentado de tal forma que reproduce una serie de diferencias sociales que los neobakalas producen y que explicaré a continuación. En la discoteca, por un lado, queda la pista de baile, donde están la mayoría de los neobakalas, por otro, la cabina del $D J$, que suele estar elevada y de frente a la pista de baile, y, por otro, el reservado, que es

22 Estilos que, ahora, abandonan su sentido vanguardista, ecléctico e innovador.

23 Este es el trabajo del $D J$. 
el espacio que muchas veces está detrás de la cabina y que alberga a los amigos íntimos de los DJ, al promotor y sus amistades y a personas de más poder adquisitivo.

Como acabo de anticipar, los neobakalas no solo producen relaciones jerárquicas hacia afuera, sino también hacia adentro. La reformulación del pasado lleva a los neobakalas a crear jerarquías internas que sitúan en la cúspide a promotores y $D J^{24}$, que casi siempre son los mismos de la época del bakalao. Los promotores son los organizadores de los eventos $y$, por tanto, son los responsables de que estos salgan bien. Esto supone que han de intentar recrear el pasado, lo que implica, por ejemplo, facilitar que haya "buen rollo», eligiendo un equipo de seguridad apropiado ${ }^{25}$, y seleccionar a los $D J$ que pondrán la música que, recordemos, debe responder a unos cánones. En esta selección de $D J$, el promotor siempre intentará contar con aquellos que pincharon en las discotecas del bakalao, que son los que más prestigio tienen y los que pueden garantizar mejor la autenticidad del relato. Los $D J$, por su parte, tienen como misión seleccionar la música apropiada para la fiesta para que el público la baile. El tercer grupo que participa en la fiesta es el de los asistentes, el público, que va a la fiesta a bailar y pasárselo bien, pero también va a juzgar la habilidad del $D J$ para seleccionar y pinchar la música del pasado. Se trata de un público que, como ya he dicho, está compuesto por personas que fueron bakalas. Pero, a diferencia de aquellos, a los neobakalas no los une tanto una estética común, un discurso corporal, sino un discurso verbal nostálgico, algo que se traduce en una gran heterogeneidad estilística en la pista de baile. La vieja unidad tribal en torno a una performance estética común en la vida cotidiana propia de los bakalas se ha perdido. En cualquier caso, la creación de esta jerarquía interna es importante porque los neobakalas, como veremos a continuación, van a jugar con ella, revertiéndola en algunos momentos, subvirtiéndola otros.

24 Recuérdese que los $D$ J, en los noventa, eran simples empleados.

25 A mediados de los años noventa, años de crisis económica, la violencia proliferó entre los bakalas debido a la falta de recursos y a la tendencia de esta cultura a la hipermasculinización (García 2010). Parte de estas actitudes han pervivido con lo que algunos neobakalas son potencialmente conflictivos. Los promotores lo saben e intentan elegir equipos de seguridad que sepan tratar con ellos de forma dialogada.
Pese a esta diferenciación social, conviene señalar que en las fiestas neobakalas solo participan neobakalas. No hay promotores ajenos a la escena que organicen estas fiestas, ni $D J$ externos a la misma que puedan actuar en ellas. En estas fiestas, donde prácticamente solo participan personas conocedoras de la misma, y que se hacen en discotecas, los neobakalas se aíslan, se repliegan hacia adentro, preparándose para representar su discurso nostálgico, para representar el pasado "tal como fue».

Resumiendo, los neobakalas viven en un cuerpo escindido, en un mundo donde se compite material y simbólicamente, un mundo lleno de rupturas y discontinuidades, tanto dentro de su propia escena, como fuera de ella, mientras al mismo tiempo albergan un deseo de unidad y unicidad. "La fiesta», en este sentido, va a desempeñar un papel fundamental tanto en la reconstrucción de continuidades, en la búsqueda de la unidad, como en la proyección de sus jerarquías, es decir, en la afirmación de su superioridad frente a otras escenas. No obstante, estos no son los únicos objetivos de los neobakalas, que también quieren pasárselo bien. Buscan pasar un buen rato al margen de la vida ordinaria, en el presente, aunque por medio del pasado. Los neobakalas, por tanto, no solo elaboran un discurso musical nostálgico mediante el cual se relacionan en su vida ordinaria con las demás escenas con las que se relacionan (especialmente en Facebook), sino que también lo practican, lo representan.

La recuperación de "la fiesta», que pretende ser "tal cual era», en un nuevo contexto, da lugar a toda una serie de paradojas, ambivalencias e inversiones. Algunas de estas ya han surgido a lo largo del texto, valga como ejemplo esta superposición del pasado sobre el presente que acabo de mencionar ${ }^{26}$ o la transformación de una identidad basada en un discurso corporal y subversivo, la de los bakalas, en otra en la que el discurso verbal gana peso para poder dominar. Estas ambivalencias, y algunas más, aparecerán en el relato etnográfico de una fiesta neobakala que voy a realizar a continuación. Espero que con él las fiestas neobakalas, y sobre todo sus protagonistas, dejen de ser una abstracción y pasen a tomar algo más de cuerpo. Nos adentramos ahora en las cosas que suceden en la vida ritual de estos sujetos.

26 Los neobakalas tratan de retemporalizar un tiempo que consideran caótico pero, al hacer esto, crean una nueva línea temporal alternativa. 


\section{RELATO DE UNA FIESTA NEOBAKALA}

Aquel viernes de mediados de noviembre Alberto se despertó por fin en casa. Llevaba diez días trabajando en Valencia con una cuadrilla de albañiles con la que colaboraba a temporadas. Alberto había tenido su propio negocio, donde trabajaba con su mujer, Tania, una carpintería que daba servicios a varias promotoras inmobiliarias cuando España iba bien. Pero cuando España fue mal, cuando los mercados financieros se colapsaron y la burbuja se pinchó, su pequeño negocio desapareció, como tantos otros, y Alberto y Tania, se fueron al paro. De todas formas, ambos volvían a tener algo de ingresos después de haber necesitado la ayuda de sus padres, ya que Tania había encontrado un trabajo en el comercio. Su situación laboral era complicada, con dificultad podían ocuparse de su hija, pero era mejor que nada. Al menos estas Navidades sí podrían comprarle algún regalo.

El día anterior a la fiesta Zolex, que caería en sábado, Alberto y Tania se quedaron en casa para descansar. Después de comer, Alberto se fue a mirar el Facebook. Lo abrió y no le gustó lo que vio en su timeline. Uno de sus amigos había puesto un post defendiendo las corridas de toros y se había liado una buena. Gente que no se conocía de nada estaba discutiendo e insultándose sin piedad. Un chico con cara de pijo estaba defendiendo las corridas como símbolo de la cultura española mientras una de sus amigas le llamaba torturador. Para colmo, uno de sus primos pequeños había compartido toda la discografía de Don Omar, el rey del reggaeton.

-Esto es un mundo de locos, qué mal rollo-, pensó para sus adentros.

Finalmente, se metió en el grupo de Zolex, que ardía en deseos de que por fin llegara la fiesta. La gente ponía los temas más potentes de la época tratando de animar lo más posible el grupo y se hacían llamadas a los fieles de la discoteca. 'Se acercaba la hora de la guerra' decían muchos, estaban 'convocados en el infierno', decían otros. El sábado iba a ser un día grande.

Revisado Facebook, Alberto se puso a poner orden entre sus cosas, coleccionaba pases de discotecas y tenía unos cuantos que eran nuevos y que quería ordenar. En ese momento llegó Tania con su hija, que fue directa a dar un beso a su padre. Tania aprovechó para llamar a su amiga Marta, que estaba en paro y con problemas con su novio, estaban peleados y la cosa no pintaba bien.

-Hola Tania.

-Qué pasa pedorra, ¿cómo vas?
-Bueno ahí voy tía, ayer lo dejé con Dani.

-Joder, tía, ¿qué tal estás?

-Pues jodida, puto capullo que me dice que no lo tiene claro. Después de dos años viviendo juntos...

-Ya tía, qué imbécil. Bueno, ya sabes que la vida sigue.

- Ya, pero otro que me sale rana.

-Bueno, ya sabes que mejor sola que mal acompañada, que le den.

- -а...

-Bueno, venga, que mañana hay Zolex. Ahí se te quitan todas las penas, ya verás.

-Sí tía, me voy a dar una fiesta que se va a cagar la perra.

Tania soltó una carcajada.

-iClaro que sí!

-Bueno nena, te dejo que tengo que hacer cosas, hablamos mañana.

-Claro, cuídate y ya sabes, lo que sea cuenta conmigo.

-iClaro! Un beso, guapa.

- Un beso.

Por la noche, Alberto y Tania se fueron pronto a la cama, había que descansar porque la fiesta iba a ser dura. Sin embargo, a los dos les costó conciliar el sueño. Estaban bastante nerviosos por la fiesta. Llevaban un año esperando. Era el momento de volver a vivir con sus amigos aquellas experiencias que tanto les habían marcado en su juventud. Para ellos era un momento verdaderamente especial.

A la mañana siguiente Tania llamó a Marta a ver qué tal iba. Tania se preguntaba cómo andaría de ánimos aquella fría mañana de noviembre.

-¡Buenas Tania!

-iQué pasa pedorra!

-iJoe no he dormido nada! ¡Qué nervios tía! ¡Tengo un nudo en el estómago, un no sé qué! ¡Estoy que me cago!

Tania soltó una carcajada.

-Sí, iAlberto también!

-iMadre mía, a ver si pasa rápido el día!

-Oye te veo bien, ¿̇cómo llevas lo de Dani?

-Bueno, ahí lo llevo tía, iQue le den! 
Tania volvió a soltar una carcajada

-¡Eso, que le den! ¡Que hoy nos vamos de fiesta!

-iClaro, tía!

-¿Cómo vas a ir?

-Pues acabo de hablar con Eduardo, el chico este que te dije que conocí por Facebook y que está haciendo un trabajo sobre música electrónica, y creo que se va a venir conmigo en el bus, así que eso haré.

-Debuti. ¿A qué hora sale?

-La peña ha quedado a las siete y media. Yo creo que a las diez estamos allí.

-Vale, pues a las diez nos vemos allí, que a nosotros nos van a acercar.

-Ok, pues allí nos vemos. ¡Beso!

-iUn beso!

A las diez y cuarto Tania y Alberto se encontraron con Marta y Eduardo en la puerta de la discoteca, que estaba situada en un polígono industrial y de la cual salía un bombo que martilleaba sus oídos. Marta, que se había encargado de comprar el temita, le dio sus pastillas a Alberto y Tania y le dijo a Eduardo que, si quería, no tenía más que decirlo. Finalmente, entraron todos juntos.

La discoteca era una enorme nave industrial rectangular de techos tremendamente altos donde cabían unas mil quinientas personas. En los laterales de la nave había algunas barras donde la gente podía comprar sus copas y, al fondo, en alto, estaba la cabina del $D J$, de donde salía un inmenso láser verde que cubría la pista. De las paredes colgaban lonas donde se proyectaban imágenes de Giger, el padre fundador de la estética de la saga Alien. Entrar en esa pista era como entrar en un espacio aislante del mundo exterior. Nada podía ser percibido de fuera, y mucho menos el sonido. La música no solo sonaba fuerte, sino que se sentía fuerte. El compás del bombo retumbaba sobre el pecho de los asistentes, haciéndolos vibrar. En ese momento estaba pinchando Master, después del cual actuarían Emmanuel Top, DJ Tote y DJ Jose.

En la pista de baile el ambiente ya se estaba caldeando. Eduardo, Alberto, Tania y Marta se dirigieron hacia la barra para pedir y Eduardo aprovechó para dar una vuelta. Eduardo era un antropólogo un tanto idealista, como un teólogo cristiano, que llevaba un par de años estudiando el bakalao y la música electrónica, sobre lo que había leído con fruición. Estaba al tanto de las últimas teorías sobre las relaciones entre la música electrónica y la religión, corriente que le resultaba especialmente interesante. ¿Acaso no eran las cabinas como altares?

No obstante, en la fiesta, Eduardo se sentía algo intimidado. Aquello estaba lleno de tipos duros de cuarenta años, mucha cabeza afeitada, mucho tatuaje y mucho olor a marihuana. Había una gran mayoría de hombres con cara de pocos amigos, con rictus serio, movimientos un tanto cortantes, muy enérgicos, incluso con un cierto halo de agresividad.

En cualquier caso, tenía que hacer su trabajo. Se dirigió al reservado para ver si podía charlar con alguien y comprobar aquello que había leído en Thornton sobre las culturas de club. Pidió permiso al equipo de seguridad que guardaba el acceso y se puso a hacer fotos con su cámara. Al poco, una de las personas que estaba en el reservado, David, se acercó a Eduardo. David era un chico bien vestido y con bastante labia. Le preguntó a Eduardo en qué medio trabajaba y si podía hacerle una foto a su hermano mayor, que estaba sentado en una de las mesas y que no podía moverse bien debido a un accidente que tuvo hace años. Después de hacer las fotos, David le ofreció a Eduardo tomar una copa de su botella y siguieron conversando. Eduardo le preguntó si lo estaba pasando bien en la fiesta y si era habitual de las mismas. David le dijo que sí, que le gustaba, pero que él no era como los de abajo. Él era un comercial que tenía su dinerillo, no era un pastillero 'colgao' como los de la pista de baile. Para él las pastillas eran de pasados aunque antes sí se las tomaba, cuando era un joven bakala. Pero ahora no, ahora prefería la farlopa y, de hecho, le ofreció a Eduardo ponerse una rayita.

Eduardo le agradeció el detalle pero lo rechazó. Miró el reloj y vio que ya era la una de la mañana. Decidió buscar a sus amigos a la pista de baile. Cuando salió del reservado y pasó a la pista, lo que vio le dejó desconcertado, le pareció grotesco incluso. Todavía estaba pinchando Master y la gente iba a saco. Las mandíbulas de muchos tendían a salirse de la cara en un movimiento incesante, otros no podían abrir los ojos, otros botaban sin piedad al ritmo de la música, otros se abrazaban hasta el infinito, otros mostraban una tremenda sonrisa que dejaba ver toda la dentadura. A decir verdad, dientes y sonrisas plagaban una pista de baile atravesada por la música y por la que circulaba de todo. Circulaba el sonido, pero circulaban también las copas, los porros, las pastillas, los gestos y las muecas. Todo parecía de todos, todos parecían interconectados.

Por fin, Eduardo dio con los demás. Alberto, como casi todos, llevaba un buen globo. Ya se había comido una pirula y luego le habían ido metiendo 
cuartitos en la boca. Igual se había comido ya dos tuercas. Alberto estaba bailando al lado de un amigo, mirando hacia la cabina. Estaba totalmente metido en la sesión de Master y, llegado un momento, agarró a su amigo Jaime por el hombro con el brazo derecho, le apretó fuerte, chocó su cabeza con él y con la mano izquierda le palmeó en la barriga. Estaba bien a gusto. Su amigo le hizo un gesto llevándose los dedos a la boca, besándoselos como quien se deleita con un plato delicioso, indicando que es de su gusto. Alberto asintió con la cabeza. Los dos estaban en la misma onda.

Eduardo, por el contrario, estaba abrumado. No estaba seguro de entender nada. Algo desesperado, agarró la copa de Marta y le dio un buen trago. Marta se echó a reír y le dijo que iba bien cargada de MDMA pero que no se preocupara, que estaba bien bueno.

-Bueno, no hay marcha atrás. ¡A la mierda!- dijo Eduardo. Y soltó una risotada.

Después de Master, entró a la cabina Emmanuel Top, al que todo el mundo esperaba. Emmanuel había sido un gran productor de trance en los noventa, con lo que la pista esperaba bailar todos sus temazos de aquellos años. Emmanuel comenzó con un house progresivo, algo trancero y con un ritmo mucho más lento que Master. Detrás de su Apple, el músico iba conectando tema con tema con precisión milimétrica gracias al programa Ableton. Al rato de empezar seguía con su house, algo más oscuro que antes, y la pista comenzó a sentirse incómoda. ¿Qué estaba pasando? ¿Qué mierda era esa? ¿Es que no sabía que estaba en Zolex y que ahí se ponía trance de los noventa? ¿Es que no sabía pinchar con unos platos?

Alberto, que se lo había estado pasando de puta madre, se empezó a mosquear. Empezó a silbar y a insultar mirando hacia la cabina del $D J$.

-iHijo de puta! ¡Vete a tu casa!

Un año esperando esta fiesta y ahora el tipo este se plantaba ahí para hacer lo que le daba la gana. Era inaceptable. A Alberto le estaba cortando todo el rollo el tipo este que iba de estrella.

Poco a poco los silbidos, los abucheos y el malestar se propagaron por la pista. La gente se fue desconectando e incluso muchos se salieron a la parte trasera de la discoteca donde había una pequeña terraza al aire libre, Alberto, Tania, Marta y Eduardo entre ellos. Antes de salir, de todas formas, Alberto aprovechó para ir al baño.

Al llegar, justo en la puerta, parecía haber algún problema. Un chico muy corpulento y una chica morena de unos cuarenta años discutían con un grupo de cinco chicos. Al parecer, uno de los del grupo más numeroso había intentado ligar con la chica. Alberto quería pasar al baño pero la situación estaba muy tensa:

-No te hagas líos conmigo y chinda, que te busco la ruina- le dijo el chico que se sentía agraviado.

Enseguida apareció un miembro del equipo de seguridad que consiguió apaciguar los ánimos y, por fin, Alberto consiguió entrar al baño donde ya varios comentaban que parecía que la gente no sabía lo que era el buen rollo.

Ya fuera, los cuatro amigos se volvieron a juntar y se pusieron a fumar porros. Estuvieron charlando un buen rato de sus cosas, de lo mal que lo estaban pasando estos años, pero también de lo bueno que era poder estar juntos en una fiesta como esta. Alberto no pudo evitar decirles que eran lo mejor y que, por mucho que se complicaran las cosas, siempre les quedaría Zolex. Al poco, Tania miró su reloj y se dio cuenta de que llegaba la hora del cierre. Se habían perdido a DJ Tote. Iba a empezar Jose.

Jose empezó con un disco de hardtrance seguido del Helena's Fantasy. Todo lo que había perdido Emmanuel Top en dos horas se lo ganaba Jose en diez minutos con dos clasicazos. La pista volvía a bullir.

Alberto, Tania, Marta y Eduardo se habían colocado en medio de la pista y bailaban compulsivamente cada golpe de bombo de la sesión, como casi toda la pista, aunque Eduardo lo hiciera de forma más torpe. Un amigo de Alberto partió una pastilla y se dedicó a dar trozos a todos. Eduardo vio cómo le metían con la mano un trozo en la boca y, agradecido, fue a la barra a coger un par de botellas de agua para todos, que no faltara de nada para nadie. Al volver vio a Marta bailando con una gorra de capitán de barco. Al ver la cara de asombro de Eduardo se la quitó y se la puso a él. No duraría demasiado la gorra en su cabeza, que fue pasando de cabeza en cabeza por buena parte de la pista.

Cuanto más fuerte se hacía la música más intensamente bailaba la gente. De hecho, la pista ya casi no bailaba sino que botaba. Su baile maquinal se estaba descomponiendo en botes al ritmo del bombo y bailes un tanto anárquicos. La pista era un desmadre. Eduardo estaba empapado en sudor y fue otra vez a la barra a por agua para todos. Era la segunda vez que lo hacía en la noche y la camarera no solo no le cobró, sino que le invitó a un chupito.

Jose estaba poniendo la discoteca patas arriba. Los porteros tuvieron que quitar el acceso al reservado 
porque todos querían salir e ir a la pista, donde más presión de sonido había. En la pista, cada golpe de bombo era demoledor. La música se había convertido en una riada capaz de arrastrar cualquier cosa.

De repente, las luces se encendieron. Eran las seis. Eduardo miró a su alrededor y vio que los rictus tan serios del principio habían mutado en sonrisas. La gente aplaudía agradecida al $D J$ y este les correspondía con el mismo gesto. Unos se miraban a otros con cara de satisfacción. El DJ había terminado la noche como debía terminar. Había sido como el Zolex original. Durante unas horas los problemas laborales de Alberto, Tania, Marta o Eduardo habían desaparecido y Marta, además, ni se acordaba de su ahora ex-novio. Eduardo no estaba seguro de entender mucho, era como si su tesis se hubiera esfumado de su cabeza para colarse en su cuerpo.

Los cuatro salieron de la discoteca y, destrozados del cansancio después de la fiesta, se fueron cada uno a su casa.

Alberto y Tania se levantaron al día siguiente poco antes de las dos de la tarde. Trataron de desayunar algo, aunque sus tripas no estaban para muchos trotes. Pasaron la tarde viendo películas. Cuando acabaron, Alberto abrió el portátil para ver qué se contaba la gente en el grupo de Facebook. Muchas personas estaban encantadas:

-Buenas tardes gente, ¿cómo vamos? ¿Estáis recuperados o aún no? Ja, ja, ja, ja, ja. Tengo que deciros una cosita, sí xk [...] sigo muy emocionada, cada vez que entro aquí [en Facebook] más aún si cabe, veo los comentarios, los vídeos, las fotos y la patata se me emociona mucho. Así que quiero deciros algo, que sois muy grandes joder (Pilar).

Otras personas, sin embargo, estaban criticando la fiesta:

-Lo siento pero este año no me ha gustado nada el cierre y lo de Emmanuel Top ha sido una mierda. Mañana haré recopilación de lo bueno (María).

-No es normal que a las 2:30 esté sonando el gabber de The Place to Be o Here is Johnny. Me gustó la sesión de Master pero demasiado cañera para esa hora... (Gerardo).

Ante las críticas, un chico llamado Óscar no dudó en responder:

-Noche para enmarcar. [...] Cuando yo empecé a salir de fiesta a Zolex la gente, sin conocerse en muchos casos, estaba a la una botando como malditos, sin molestarse [...] Era un EXTASIS total, [...] se veía en las caras... radiaban alegría, una expresión de felicidad [...] cualquier rostro que miraras [te de- volvía] una sonrisa de oreja a oreja y una mirada que llenaba el ser [...] Yo [ayer] viví esa esencia y con esa música de antaño y con esa gente de antaño [...] Todos sabemos cómo lo hicieron los artistas, es más ellos los primeros, es muy fácil criticar y sobre todo menospreciar :)) Depende de cada uno, de lo que quiera dar y cómo se encuentre, lo difícil es construir... para mí todos estuvieron bien. Yo animo a los de Zolex a que escriban su experiencia, cuando empezaron a salir de fiesta, las historias serían cultura e historia y recuerdos y risas. Qué os parece, lo mismo escribimos un libro (Óscar).

En fin, tiene que haber gente para todo, pensó Alberto mientras apagaba el ordenador. Se estaba haciendo tarde y el lunes ya le tocaba viajar con la cuadrilla...

\section{ASPECTOS RITUALES}

Pasemos ahora a analizar los distintos matices de las fiestas neobakalas y sus transformaciones. Poco antes de iniciar este relato, señalé que la fiesta neobakala está regida por unas reglas que deben asegurar que la fiesta «recuerde» el pasado o, mejor dicho, que se represente el relato de la nostalgia y los valores de la comunidad: el vinilo, el "buen rollo», la no sexualización de la pista de baile o el esfuerzo físico. La existencia de estas reglas es la que nos permite entender buena parte de las actitudes de los neobakalas durante la fiesta como, por ejemplo, cuando los neobakalas abandonan la pista de baile cuando está actuando Emmanuel Top, momento en que Alberto le manda "a tomar por culo». Esto lo hacen porque este artista no estaba observando las reglas de la comunidad. Al estar poniendo música contemporánea con tecnología digital (el programa Ableton desde un ordenador) y sin ningún esfuerzo, Emmanuel Top no estaba respetando las reglas de la fiesta. Del mismo modo, DJ Master fue reprobado al día siguiente de la fiesta por Gerardo por poner música demasiado rápida y contundente (Here is Johnny) a las 2:30. Ese no era el momento para ese tema.

Estas reglas también aparecen en otros episodios del relato, como cuando Alberto se dirige al baño y no puede entrar porque hay una disputa entre una pareja y un grupo de amigos porque uno de ellos ha intentado ligar con la chica de la pareja ${ }^{27}$. El hombre

27 Recuérdese que el malestar, la frustración y la masculinidad acompañan a estas personas a la pista de baile, especial- 
que intentaba ligar estaba infringiendo las reglas de la comunidad, porque a las fiestas neobakalas no se va a ligar. Como decía, para los neobakalas la pista de baile ha de ser un lugar desexualizado. No obstante, este episodio se resuelve de forma relativamente amistosa, porque el «buen rollo» ha de prevalecer en la medida de lo posible. Es por eso por lo que el empleado de seguridad, que ha sido informado previamente del ambiente que debe reinar en la sala, actúa de forma comedida, intentando calmar los ánimos. Otro de los aspectos rituales de la fiesta es el "buen rollo», que ya no es solamente algo que surja durante la fiesta, sino que debe surgir. El «buen rollo» de las fiestas neobakalas es, por tanto, una ritualización del «buen rollo» de "la fiesta» de los bakalas que daba lugar a la communitas. Liberarse, chocarse con alguien y pedirle disculpas, respetar, sonreír, ser amable, bailar, conocerse, empatizar o abrazarse ya no son actividades que simplemente surgen, sino que se esperan. Esto no quiere decir que el «buen rollo» nunca aparezca de forma «espontánea» y que siempre sea representado, si es que acaso hay alguna diferencia entre ambos. Sea como sea, cuando Alberto está bailando con su amigo y le abraza en la pista de baile o cuando Eduardo va a por agua para todos después de que le inviten a una pastilla, ambos están de «buen rollo».

El hecho de que en la fiesta neobakala se produzca la representación de un discurso y que para ello se estipulen unas reglas ya sugiere con cierta claridad el aspecto ritual de la misma. Pero, además de esto, hay que señalar que la fiesta neobakala, como muchos rituales (Turner 1982 y 1988), se puede dividir en tres partes: hay un antes, un durante y un después. El antes lo constituye el tiempo de la espera y de la preparación. Es un tiempo que, como hemos visto, es de mucha actividad en las redes sociales, en las que se da una cierta efervescencia, una intensificación del ritmo de publicaciones de los miembros de la comunidad. Es un tiempo que se vive con muchos nervios, como vimos en el caso de Alberto o Marta, en el que los días previos cuesta incluso conciliar el sueño. El paso a la siguiente fase viene marcado por la llegada a la fiesta, por el paso de la puerta, el umbral. El punto de corte lo marca la puerta misma $y$, en el interior, la música, las luces y el consumo de

mente a los hombres que a veces pueden mostrarse agresivos, como muestra este episodio que aparece en el relato. El "buen rollo», la fiesta, es una forma de lidiar con ello. psicoactivos. Una vez dentro de la discoteca, los neobakalas se han separado de la sociedad en su conjunto, a la que no se puede ver ni oír. A partir de ese momento los neobakalas solo tienen un punto de referencia social que es el suyo propio. Es en este momento cuando los neobakalas se disponen a entrar en un estado liminal. Por último, hay un después de la fiesta que viene marcado por la vuelta a casa, al uso de las redes sociales y a las obligaciones laborales (si es que se tienen). Es, como ellos dicen, un volver a la vida real.

\section{ASPECTOS CARNAVALESCOS}

Junto a los aspectos rituales de las fiestas aparecen otros que podríamos denominar carnavalescos (Bajtín 1989). En este sentido, expresiones empleadas por los neobakalas como «ir del revés», "pillar un ciego» 28 o "poner la discoteca patas arriba» no pueden ser más carnavalescas, lo mismo que los abrazos, las sonrisas y los palmoteos en la barriga. Por otro lado, las imágenes de mandíbulas que se escapan del cuerpo y de las bocas como lugares de tránsito que comunican distintos espacios no dejan de recordarnos todas aquellas imágenes de la cultura cómica popular de la que hablaba Bajtín. En la fiesta neobakala, las pastillas no se toman, sino que "se comen" y no son buenas, sino que «están buenas». En la fiesta los neobakalas se alimentan de música, de pastillas, de sonrisas, de abrazos. En la fiesta neobakala se abren las puertas de la casa (las bocas), donde entran los demás (los dedos), todo es distribuido profusamente (pastillas, agua, copas o tabaco), hay bromas, danzas y el igualitarismo de un mundo utópico.

En la fiesta neobakala, además, la estrella, el rey, el $D J$, puede ser juzgado, vilipendiado, degradado. Es por esto por lo que Alberto se siente perfectamente legitimado para insultar a Emmanuel Top y mandarle "a tomar por culo». Durante la fiesta neobakala, la estructura social de la escena se invierte y el neobakala es el rey. Es por y para ellos, y es por esto por lo que dicen que "se van a dar una fiesta», como señala Marta. En la fiesta neobakala, en definitiva, el orden se invierte y las reglas de la vida ordinaria se

28 Nótese que esta expresión explicita que lo que se anula es la vista, el centro de los sentidos. El carnaval también es sensorial. 
suspenden. Por eso también se puede dar, invitar, compartir y se dan las gracias.

Este carácter carnavalesco también lo podemos observar en la figura de Eduardo, un antropólogo idealista que en la fiesta está desubicado, le cuesta entender y se siente incómodo al ver los rostros desencajados en la pista de baile. Es por este tipo de intelectualidad metafísica y racionalista que Eduardo piensa el episodio como "grotesco» (en el sentido decimonónico de la palabra). Es por esto por lo que Eduardo solo empieza a entender cuando deja de pensar en Thornton y se deja llevar por la música, el baile o las drogas.

Por otro lado, en la fiesta neobakala la música llega a ser violenta, martilleante. Es una música que penetra, que arrasa, que destruye. Es una música que es física, que se escucha tanto como se siente. Igual que el láser, que se ve igual que se toca. En la fiesta neobakala, el oído y el tacto parecen, cuanto menos, igualarse a la vista, con lo que se puede decir también que el orden de los sentidos se relaja, se subvierte. Después de la fiesta, por último, uno queda «muerto» o "destrozado». Pero es una muerte que da vida, que, como veremos ahora, cambia los estados afectivos.

\section{LA MAGIA Y LA TRANSFORMACIÓN DE LOS AFECTOS}

La magia está relacionada con mirar a una persona y saber que está en el mismo punto que tú. Pero la magia no la generan las drogas sino el ambiente, la música... es una suma de cosas. No se puede asociar el que te lo pases bien solo a que te comas una pastilla... ni una pastilla, ni una raya ni MDMA ni nada [...] la magia que lo envuelve todo es poder disfrutar con tus amigos de la música que te ilusiona... [...] Es como poner un paréntesis a la rutina y estar ahí metida... Entonces, mientras lo estás preparando estás ilusionado...y eso te ayuda a sobrellevar... la semana, el estrés, el no sé qué... [...] te sirve para... para... para seguir... (Ana).

No nos cansaremos nunca de transmitir energía positiva para que podamos afrontar las tempestades y luchas que se nos presentan en nuestro camino diario (Zolex).

En la communitas espontánea proliferan los sentimientos, sobre todo los agradables, mientras que la vida en la 'estructura' está llena de dificultades objetivas: han de tomarse decisiones, los gustos han de sacrificarse a los deseos y necesidades del grupo, y los obstáculos físicos y sociales deben superarse con un cierto coste personal. La communitas espontánea está rodeada por un algo 'mágico'; desde un punto de vista subjetivo comunica la sensación de un poder ilimitado (Turner 1988: 145).

Como ya he explicado, la acción dentro de la fiesta neobakala se orienta hacia la representación de un discurso nostálgico y, por tanto, a la disolución de la discontinuidad entre el presente y el pasado idealizado. De todas formas, como también he señalado ya, los neobakalas no buscan solo eliminar las discontinuidades temporales sino también las sociales. En la fiesta, el neobakala estrecha el mundo, lo reduce, una vez pasa por la puerta de la discoteca. Una vez allí, se aísla del mundo exterior, quedando solo su propia estructura social (promotor, DJ, asistente). Cuando Alberto, Marta, Tania y Eduardo entran a la fiesta, lo hacen a un espacio que todavía está fragmentado socialmente. Cuando entran en la discoteca acceden a un espacio que está dividido entre la cabina del $D J$, el reservado y la pista de baile. Cuando Eduardo entra en el reservado de la fiesta y tiene la conversación con David, que le dice que él es muy distinto de los demás porque tiene un buen trabajo y toma coca en lugar de pastillas, esto nos está informando de la pervivencia de diferencias sociales.

Este aspecto es importante porque el flujo de la acción dentro de la fiesta neobakala se orienta, en gran medida, y siempre siguiendo las reglas que he descrito, a la eliminación de estas diferencias. Una música reglada, pinchada de una determinada manera, con un determinado volumen, acompañada de unas reglas de comportamiento que intentan promover el «buen rollo» (los abrazos, las sonrisas, la empatía, la reciprocidad) son la vía para eliminar la estructura social, tanto la interna como la externa. Es por medio de estas reglas, del flujo de la música y el baile, de las luces y el láser, de las diferentes drogas y de las proyecciones en pantallas que los neobakalas crean un espacio liminal donde todos pueden ser como si fueran uno, como si no hubiera diferencias sociales, aunque sea, como dice el promotor de la fiesta Zolex, «tan solo un instante, tan solo un momento».

Es a través de la música, del baile y de las sustancias que se toman (de la acción corporal) que se abolen las diferencias y los roles de la vida cotidiana ${ }^{29}$, tanto los de la vida urbana como los propios de los

29 No hay que olvidar, además, que la masculinidad también se relaja en la fiesta, lugar donde no está bien vista la 
neobakalas. En realidad, las reglas de la fiesta neobakala funcionan a la inversa que en la vida ordinaria. En la fiesta neobakala se comparte, se invita, se abraza, se sonríe; muy al contrario de lo que pasa en la vida ordinaria donde, como dicen ellos, «no se dan ni las gracias». En la fiesta neobakala todos pueden jugar un papel importante y, en ciertos momentos, todos pueden ser como si fueran iguales, sin distinción. En ciertos momentos, la música, el baile y las drogas son capaces de suspender las diferencias e interconectarlos a todos. Como aquel cierre que describí en el relato, en el que DJ Jose puso la pista «patas arriba», cuando se eliminó la barrera del reservado y desaparecieron las diferencias sociales. Esta es la magia de la que habla Ana, la que permite «afrontar las tempestades y luchas que se nos presentan en nuestro camino diario".

En cierto sentido, de lo que habla Ana en la cita que encabeza este apartado es de la communitas, que es el concepto más cercano a sus propias concepciones, porque los neobakalas hablan de estar juntos, de mirar a una persona y saber «que está en el mismo punto que tú», porque es en esta fiesta donde los neobakalas pueden experimentar un «vínculo social generalizado», "un sentimiento de entendimiento mutuo a un nivel existencial, ese momento en el que sientes que todos los problemas, bien sean emocionales o cognitivos, bien sean propios o ajenos, pueden ser resueltos» (Turner 1982). Son los propios informantes los que al hablar de la magia parece que hablen de la communitas y sus sensaciones agradables $^{30}$. Esta magia, como dice Óscar cuando dice que a él sí le gustó la fiesta, es interpretada por muchos como la esencia de la fiesta.

En la fiesta neobakala el flujo de la música y la acción son capaces de arrastrarlo todo, integrarlo. La fiesta se presenta, por tanto, como un evento con gran capacidad aglutinadora. La música en la fiesta neobakala es continua, como un río capaz de integrar no solo las diferencias sociales, sino también los sentidos y la escisión de la persona. Como señalaba uno los carteles de la fiesta Zolex, en la fiesta, «cuerpo y alma se unirán en un abrazo sin separación».

La fiesta neobakala es capaz de resolver problemas derivados de la desigualdad social y de las rupturas

depredación femenina, y donde los hombres pueden abrazarse e incluso besarse.

30 Quizás, porque todos comparten una tradición o cuerpo cristiano. temporales. Es un evento con gran poder aglutinador $y$, en cierto sentido, subversivo, que facilita la transformación de los estados de ánimo. Los neobakalas, por medio de la fiesta, son capaces de producir sonrisas, empatía y reciprocidad. Construyen otro mundo, por medio de la nostalgia, que les sirve, como decía Ana, «para seguir». De esta forma los neobakalas pueden transitar del malestar, la frustración o la insatisfacción a un estado de empoderamiento y satisfacción. En el caso particular de los hombres, además, sus rostros pasan a lo largo de la fiesta de una cierta agresividad a la relajación. De las tristezas los neobakalas pasan a las alegrías. De este modo, Pilar, por ejemplo, pasa varios con la "patata emocionada», Óscar propone escribir un libro y Marta ya no se acuerda de su fracaso amoroso o su situación de desempleo.

La communitas, la unión, en cualquier caso, es temporal. Una vez pasada la fiesta, la comunidad retorna al mundo digital, donde los participantes expresan sus opiniones de la fiesta. Es la fase de reintegración (que en este caso es desintegración). En cierto sentido, se vuelve de lo performativo, corporal y sensible a lo discursivo, es decir, al discurso verbal de la nostalgia. Con este paso vuelven las jerarquías y los límites que existen dentro del grupo, y las que existen entre este, generalmente es de clase trabajadora, y el resto de la sociedad. Después de la fiesta vuelve la discordia. Para unos, unos $D J$ lo hicieron bien y para otros mal, como para María, que no le había "gustado nada el cierre» de Jose. La unidad, la utopía, es un objetivo no manifiesto de la fiesta que no siempre se alcanza y que cuando se alcanza, se rompe rápidamente hasta la siguiente fiesta. Ahora bien, con la realización de la fiesta los neobakalas han afirmado, en cualquier caso, la existencia y superioridad de un relato nostálgico que les permite proyectarse sobre los otros: los seguidores de la EDM, del reggaeton o del minimal-techno.

\section{CONCLUSIONES}

¿Qué es la fiesta neobakala? ¿Un ritual?, ¿Una conmemoración? ¿Un carnaval? Clasificarlo de una u otra manera sería una forma de reducir un evento que está lleno de ambivalencias. Por tanto, a pesar de que distintos autores, como Turner (1982), diferenciaran entre carnavales, ceremonias y rituales, lo cierto es que las fiestas neobakalas tienen mucho de 
ritual, de carnaval, de ceremonia y de fiesta, en este caso conmemorativa.

Las fiestas neobakalas no responden a las necesidades del investigador, sino a las de las personas que la protagonizan. Se trata de una práctica creada para responder al contexto en el que estas personas se desenvuelven. Un contexto lleno de rupturas, sociales y temporales, que dan lugar a una serie de estados afectivos (inseguridad, frustración, insatisfacción, agresividad, nostalgia) que las fiestas permiten transformar, reconstruyendo la continuidad (temporal, social, sensorial y personal). Si el contexto impone divisiones, fracturas, desigualdades, jerarquías y exclusiones la fiesta neobakala aporta unidad, igualdad, continuidad y participación ${ }^{31}$. Es de esta forma que pasan de las tristezas a las alegrías, de padecer a obrar, y es de esta forma que satisfacen la necesidad de la persona capitalista de estar contenta (todajunta-dominada-retenida), cuando la capacidad de consumo es muy limitada. En cierto sentido, los neobakalas tratan de resolver simbólicamente lo que no pueden resolver materialmente.

Por otro lado, las fiestas constituyen el espacio en el cual los neobakalas representan, disuelven y afirman su identidad, que se basa en un relato nostálgico que toma elementos del pasado bakala. Este relato, a su vez, les permite proyectarse jerárquicamente hacia otras escenas musicales con las que se relacionan: el reggaeton, la EDM y el minimal-techno. Escenas que generalmente identifican con migrantes latinos y jóvenes, precisamente aquellos que, en forma de repliegue les recuerdan sus rupturas. El joven le hace patente al neobakala el final de una juventud idealizada mientras que el migrante le recuerda la heterogeneidad del espacio. Sobre estos grupos los neobakalas se despliegan con toda una serie de discursos destinados a la dominación. El otro en el sí mismo, la interoceptividad (Surrallés 2005), en un momento de crisis y cambio tecnológico, se vive con tristeza, y el sí mismo en el otro, la exteroceptividad (Surrallés 2005), se entiende como un «torpe» o un «vicioso».

Para terminar, me gustaría hacerlo reflexionando sobre las relaciones entre memoria y nostalgia. La cultura neobakala, aunque toma elementos del pasado, los reformula de forma tan embellecida que

31 En este sentido, recuerda a la carrera korrika estudiada por Teresa Del Valle (1988) termina por erosionar su propia memoria. De esta forma, en este relato tan embellecido, apenas queda espacio para las condiciones que dieron lugar al bakalao. La precariedad juvenil en la que nació, sus propios excesos o la represión se olvidan. Como señala Tomé (2016), la nostalgia deshistoriza el pasado. Los neobakalas crean un relato y una práctica que dice ser igual que en el pasado, pero no lo es. Usan algunos de sus materiales, pero en un contexto y con una finalidad diferente. Esto no quiere decir, no obstante, que no produzcan memoria. Cuando bailan, cuando ríen, cuando se palmotean en la tripa, cuando dan, reciben y devuelven... Estas prácticas o actitudes corporales (Connerton 1989) sí recuerdan el bakalao e incluso tiempos y espacios más lejanos (Díaz Viana 2005).

\section{BIBLIOGRAFÍA CITADA}

Anta Félez, José Luis. 2007. Segmenta antropológica. Un debate crítico con la antropología social española. Granada: Universidad de Granada.

Appadurai, Arjún. 2001. La modernidad desbordada. Dimensiones culturales de la globalización. Buenos Aires: FCE.

Appadurai, Arjún. 2016. Banking on Words: The Failure of Language in the Age of Derivative Finance. Chicago: The University of Chicago Press.

Bajtín, Mijaíl. 1989. La cultura popular en la Edad Media y en el Renacimiento. Madrid: Alianza.

Bhabha, Homi. 1994. El lugar de la cultura. Buenos Aires: Manantial.

Bourdieu, Pierre. 2003. "Participant Objectivation». Journal of the Royal Anthropological Institute (N.S.), 9: 281-294. doi: <https://doi.org/10.1111/1467-9655.00150>.

Butler, Judith. 2007. El género en disputa. Barcelona: Paidós.

Connerton, Paul. 1989. How Societies Remember. Cambridge: Cambridge University Press.

Connor, Steven. 2004. «Edison's Teeth: Touching Hearing» en Veit Erlmann (ed.), Hearing Cultures. Essays on Sound, Listening and Modernity: 153-172. Oxford: Berg.

Díaz G. Viana, Luis. 2005. "Los caminos de la memoria: oralidad y textualidad en la construcción social del tiempo». Acta Poética, 26, 1-2: 181-217. doi: < https://doi.org/10.19130/ iifl.ap.2005.1-2.169>.

Feixa, Carles. 1998. De jóvenes, bandas y tribus. Barcelona: Ariel.

Feixa, Carles, Ariadna Fernández-Planells y Mónica FiguerasMaz. 2016. «Generación Hashtag. Los movimientos juveniles en la era de la web social». Revista Latinoamericana de Ciencias Sociales, Niñez y Juventud, 14: 107-120. 
García García, Antonio. 2008. "¿Qué le pasa a los hombres?: A propósito de las dinámicas identitarias masculinas en la modernidad tardía». Arxius de sociologia, 19: 41-51.

García García, Antonio. 2010. «Exponiendo hombría. Los circuitos de la hipermasculinidad en la configuración de prácticas sexistas entre varones jóvenes». Revista de Estudios de Juventud, 89: 59-78.

Gutiérrez Estévez, Manuel. 2006. «Sentido común y sueño de los sentidos», en Beatriz Muñoz González y Julián López García (coords.), Cuerpo y medicina: textos y contextos culturales: 57-84. Cáceres: Cicon.

Gutiérrez Estévez, Manuel. 2009. «Ambivalencias elementales. Representaciones amerindias». Quaderns de I'Institut Català d'Antropologia, 25: 141-160.

Hirai, Sinji. 2009. Economía política de la nostalgia: un estudio sobre la transformación del paisaje urbano en la migración transnacional entre México y Estados Unidos. México: Universidad Autónoma Metropolitana, Unidad Iztapalapa.

Leste, Eduardo. 2018. Memoria y nostalgia en la industria musical: el caso de la música electrónica. Tesis doctoral inédita, Universidad Complutense de Madrid.

Leste, Eduardo. 2020. «Identidad, memoria y nostalgia de la escena neobakala madrileña». Revista de Antropología Social, 29(1), 1-15.

Levin, David. 1993. Modernity and the Hegemony of Vision. Berkeley: University of California Press.

Marcus, George y Michael Fischer. 1986. «La repatriación de la antropología como crítica cultural», en La antropología como crítica cultural. Un momento experimental en las ciencias humanas: 169-202. Buenos Aires: Amorrortu.

Martínez Noriega, Dulce Asela. 2014. «Música, imagen y sexualidad: el reggaetón y las asimetrías de género». El Cotidiano, 186: 63-67.

Mauss, Marcel. 2002. The Gift. The Form and Reason for Exchange in Archaic Societies. Londres: Routledge.

Micarelli, Giovanna. 2018. «Investigar en un mundo encantado: los aportes de las metodologías indígenas al quehacer etnográfico». Universitas Humanística, 86: 219-245. doi: <https://doi.org/10.11144/javeriana.uh86.imei>.

Observatorio Metropolitano. 2007. Madrid: ¿la suma de todos? Globalización, territorio, desigualdad. Madrid: Traficantes de sueños.
Said, Edward. 2001. "Cultura, identidad e historia», en G. Schröder y $\mathrm{H}$. Breuninger (comps.), Teoría de la cultura. Un mapa de la cuestión: 37-53. Buenos Aires: FCE.

St. John, Graham. 2008. Victor Turner and Contemporary Cultural Performance. Nueva York: Berghahn.

St. John, Graham. 2014. «Liminal Being: Electronic Dance Music Cultures, Ritualizationand the Case of Psytrance», en Andy Bennet y Steve Waksman (eds.), The SAGE Handbook of PopularMusic: 243-260. Londres: SAGE.

Straw, Will. 1991. "Systems of Articulation, Logics of Change: Communities and Scenes in Popular Music». Cultural Studies, 5, 3: 368-388. doi: <https://doi.org/10.1080/ 09502389100490311>.

Surrallés, Alexandre. 2003. «Face to Face: Meaning, Feeling and Perception in Amazonian Welcoming Ceremonies». Journal of the Royal Anthropological Institute (N.S.), 9: 775-791. doi: <https://doi.org/10.1111/j.1467-9655.2003.00173.x>.

Surrallés, Alexandre. 2005. "Afectividad y epistemología en las ciencias humanas». AIBR. Revista de Antropología Iberoamericana. Núm. Especial. Noviembre-Diciembre 2005. Disponible en: <http://www.aibr.org/antropologia/44nov/ articulos/nov0502.pdf>.

Surrallés, Alexandre. 2009. «De la intensidad o los derechos del cuerpo. La afectividad como objeto y como método». Runa, 30, 1: 29-44.

Tomé, Pedro. 2016. «Paisajes serranos en una economía política de los sentimientos», en Luis Díaz Viana y Dámaso Javier Vicente Blanco (eds.), El patrimonio cultural inmaterial de Castilla y León: propuestas para un atlas etnográfico: 161-182. Madrid: CSIC.

Tomé, Pedro. 2017. «La nostalgia como cronopolítica. A propósito de los paisajes y las gentes de Gredos». Reflexiones Rayanas, 2: 221-240. Ávila: Asociación de Antropología de Castilla y León.

Turner, Victor. 1982. From Ritual to Theatre. The Human Seriousness of Play. Nueva York: PAJ.

Turner, Victor. 1988. El proceso ritual: estructura y antiestructura. Madrid: Taurus.

Valle, Teresa del. 1988. Korrika: rituales de la lengua en el espacio. Barcelona: Anthropos. 